\title{
Sobre a orientação econômica do partido da Frente Nacional (Front National)
}

Fabien Tarrit

Universitè de Reims Champagne Ardenne - França

\section{Resumo}

Na tradição fascista, no coração da qual foi fundada, a Frente Nacional é um partido burguês que defende de forma inequívoca o capitalismo, particularmente o capital industrial nacional enfraquecida pelo aumento do capital financeiro. Para defender o seu eleitorado tradicional, a pequena burguesia (artesãos e comerciantes) enfraquecidos pela competição, ele defende o Estado forte limitado às suas funções repressivas. Ele tenta expandir seu eleitorado, dirigindo-se aos trabalhadores, enquanto procura enganar os sindicatos enfraquecendo e dividindo os trabalhadores franceses e trabalhadores estrangeiros. É principalmente um inimigo para os trabalhadores e, por vezes, desempenha o papel de estímulo para partidos burgueses tradicionais.

Palavras-chave: Frente Nacional, neofascismo, direita, política francesa, classes sociais.

\section{Résumé}

Dans la tradition fasciste au cœur de laquelle il a été fondé, le Front national est un parti bourgeois qui sans ambiguïté défend le capitalisme, et en particulier le capital industriel national affaibli par l'essor du capital financier. Pour défendre son électorat traditionnel, la petite-bourgeoisie (artisans et commerçants), fragilisée par la concurrence, il défend un État fort limité à ses fonctions répressives. II tente d'élargir son électorat en s'adressant aux travailleurs, tout en cherchant à les tromper en affaiblissant les syndicats ouvriers et en divisant les travailleurs français et les travailleurs étrangers. II est avant tout un ennemi pour les travailleurs et joue parfois le rôle d'aiguillon pour les partis bourgeois traditionnels.

Mots clés: Front national, neofascisme, droite, politique francaise, classes sociales

\section{Abstract}

Within the fascist tradition in which it was founded, the National Front as a bourgeois party unambiguously defends capitalism, especially industrial capital which has been weakened by the development of financial capital. In order to defend its traditional electorate, the petite-bourgeoisie (craftsmen and shopkeepers) which has been weakened by competition, it advocates a strong State circumscribed to its repressive functions. It attempts to enlarge 
its electoral basis in addressing the workers, whereas he tries to cheat them in weakening the workers' unions and in dividing the French workers and the foreign workers. It is first of all an enemy for the workers and it sometimes acts as a spur for the traditional bourgeois parties.

Key words: National Front, neo-fascism, right, French politics, social classes.

\section{Resumen}

En la tradición facista y en su centro en el cual en fué fundado, el partido del Frente Nacional es un partido burgués que, sin ninguna ambigüedad, defiende el capitalismo, y en particular el capital nacional industrial debilitado por el desarrollo del capital financiero. Para defender sus electores tradicionales, o sea, la pequeña burguesía (artesanos y comerciantes) debilitados por la concurrencia con otros, el defiende un estado fuerte limitado a sus funciones de represión. El intenta aumentar el número de sus electores dirigiéndose a los trabajadores buscando al mismo tiempo engañarlos debilitando los sindicatos obreros y dividiendo los trabajadores franceses y los trabajadores extranjeros. El partido del Frente Nacional es sobre todo un enemigo de los trabajadores y hace a veces el papel de estimula para los partidos burgueses tradicionales.

Palabras clave: Frente Nacional, neofascismo, derecho, clases sociales.

A Frente Nacional (FN) foi fundada em 1972 por Nova Ordem (Ordre nouveau), uma organização fascista composta por partidários do marechal Pétain, antigos carrascos e torturadores da guerra da Argélia, por líderes católicos, tendo como dirigente Jean-Marie Le Pen. Sua filha, Marine Le Pen, ocupa seu lugar em 2011. Desta forma, a FN não sai do movimento operário, mas da fração mais reacionária da burguesia. É um partido burguês, defende o capitalismo: "Nós não colocamos em questão a economia de mercado, nem os benefícios da concorrência se ela é legal". Trata-se de "reencontrar a competitividade" e de lutar "contra a concorrência internacional desleal" (Marine Le Pen, Le Monde, 20 de setembro de 2012). Mesmo se esse partido não é - a rigor - um partido fascista, no sentido em que ele pretende inscrever-se na democracia parlamentária, ele se situa, sem ambiguidade, nessa tradição. A FN defende um Estado forte a serviço da pequena burguesia tradicional fragilizada pela concorrência (1). Sobre esse aspecto ele não ataca a grande burguesia, mas sim a classe dos trabalhadores, sempre tentando enganá-la para ganhar seus sufrágios (2).

É também contra o estrangeiro que a FN concentra grande parte da sua ofensiva, particularmente para dividir os trabalhadores, opondo os de nacionalidade francesa aos trabalhadores imigrantes através de uma política de preferência nacional (3).

\section{Um estado forte em apoio à pequena burguesia tradicional e ao capitalismo industrial enfraquecidos ambos pela concorrência}

Enquanto as principais correntes burguesas defendem o capital nacional em sua concorrência contra os capitais de outros países, o fascismo se dirige tradicionalmente 


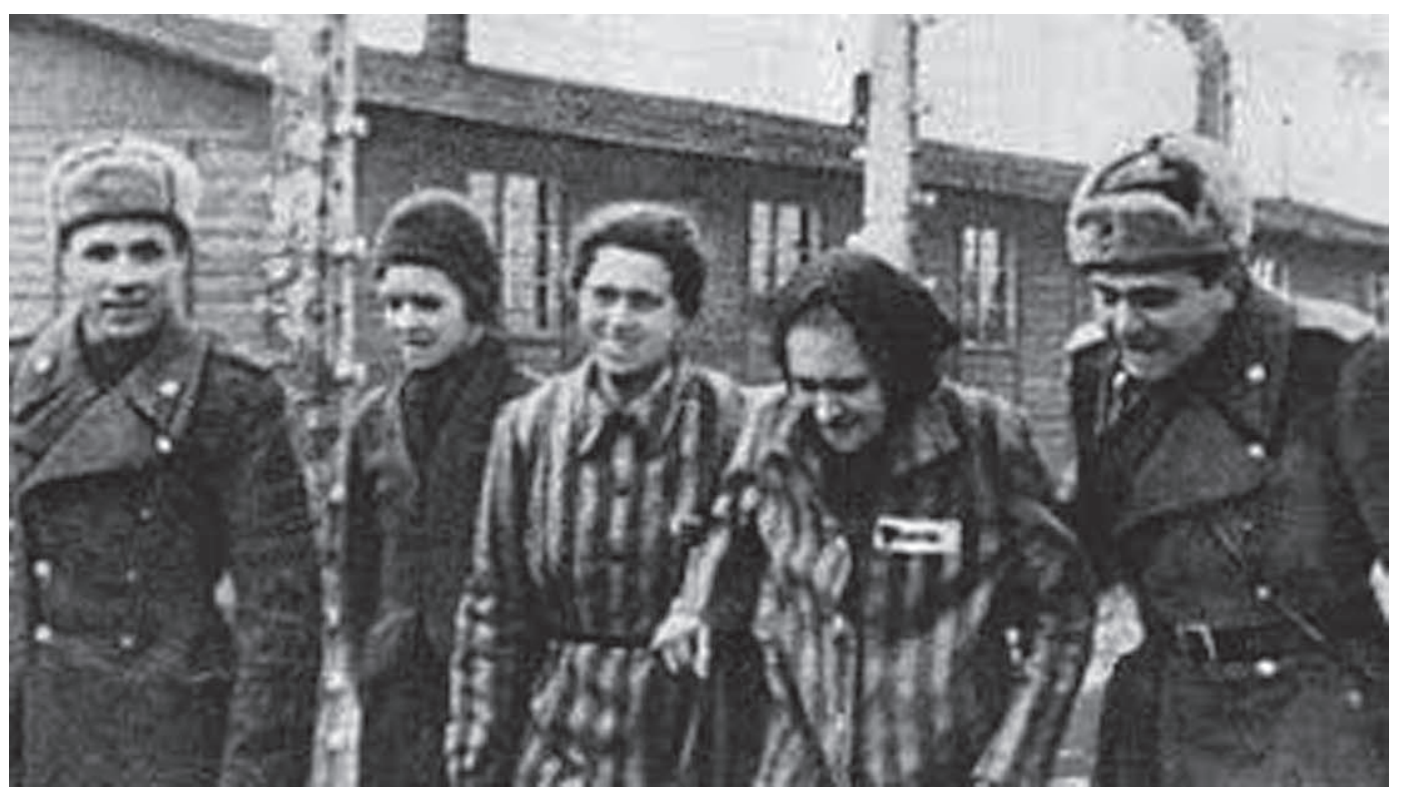

Exército Vermelho liberta campos de concentração nazistas.

a pequena burguesia arruinada pelas devastações que lhe são infligidas pelo capitalismo na sua fase imperialista, em particular pelo capital financeiro.

"Através dos agentes do fascismo, o capital põe em movimento as massas da pequena burguesia colérica, os bandos de lumpen-proletários desclassificados e desmoralizados, todos esses incontáveis seres humanos que o próprio capital financeiro mergulhou no desespero”. (Trotsky “Democracia e fascismo”, 1932).

Sob esse aspecto a FN recomenda a reindustrialização e o apoio as PME (pequenas e médias empresas) diante da crise. Desse modo, ela assim procura dar uma "prioridade absoluta ao desenvolvimento dos artesãos e dos comerciantes que são criadores evidentes" (Programa Político da Frente Nacional), gabando-se assim de sua capacidade de ser um dos "vetores insubstituíveis do elo social" e de encarnar o "refinamento de nossa civilização”, postulando dessa maneira a superioridade da civilização ocidental. Concretamente, a FN propõe a criação de novas fatias intermediárias do imposto sobre os ganhos, para "torná-lo mais progressivo", de tal modo que "as classes médias pagarão menos imposto sobre o que ganham, mas os lares mais abastados pagarão mais". Ela propõe assim diminuir o salário diferido da classe assalariada exonerado-a de 200 euros do pago de cotizações sociais patronais, abusivamente qualificados de cargos sociais, todos os salários inferiores a 1,4 vezes o SMIC, ou seja, o salário mínimo. Essa exoneração seria financiada pelos direitos de alfândega denominados "contribuição social às importações”.

$\mathrm{Na}$ realidade, é menos a pequena burguesia que o capital nacional, defendido pela FN, mas não todo o capital; unicamente sua fração industrial contra sua fração financeira. O objetivo da FN é o de um "bom” capitalismo articulado ao redor de capital industrial, contra um "mau" capitalismo que tem uma dominante financeira:

“As 50 mais fortes capitalizações da bolsa ... deverão atribuir 15\% de seu resultado líquido em reserva especial de reindustrialização. Essas somas serão postas à disposição 
de fundos de investimento estratégicos durante cinco anos e serão restituídas ao final desse periodo". (Programa da FN)

Contra o capital financeiro, este partido é favorável a uma separação legal entre bancos de depósito e bancos de negócios; é favorável a uma nacionalização, em certas circunstâncias, dos bancos do depósito em dificuldade a uma interdição dos "produtos derivados especulativos", e mesmo a uma taxa "mundial" sobre as transações financeiras. Trata-se também de formar as elites ("as grandes escolas") nos ofícios de empresariado e de indústria mais do que nos ofícios que têm a ver com a finança. A defesa da empresa, que é na realidade, a do capitalismo industrial, será ensinada à juventude nos liceus e colégios, com o ensino do "espírito de empresa", com um enfoque particular sobre a "contribuição das pequenas empresas à vitalidade econômica do país... como o ponto lançador da atividade econômica e do emprego". Trata-se também de adaptar a formação às necessidades do capital suprimindo o colégio único - que oferece a mesmo ensino a todos os alunos - e de oferecer mão de obra muito barata às empresas - sobretudo os PME [Pequenas e médias empresas] - reforçando as filiais profissionais, aumentando o número de aprendizes - de 500000 a $700 \quad 000$ - e avançando a idade a 14 anos contra os de 16 de hoje.

Tudo isso faz eco à tradição programática dos partidos fascistas para quem o capital financeiro coloca em perigo a pequena burguesia. Alguns meses antes de se tornar o partido nazi, o partido operário alemão, DAP, adotava um programa (O programa de 25 pontos do Partido operário alemão nacional-socialista) no qual ele se pronuncia por:

“... a supressão da escravidão de interesse... a nacionalização de todos as empresas que hoje pertencem a trusts... uma participação nos benefícios das grandes empresas... a entrega imediata das grandes lojas de administração comunal (das pequenas cidades, dos lugarejos) e de seu aluguel, a preços baixos, aos pequenos comerciantes... a promulgação de uma lei permitindo a expropriação, sem indenização, de terrenos com fins de utilidade pública".

A FN tem necessidade de um Estado forte que pretenda estar a serviço das PME, das PMI (Pequenas e médias indústrias) e da indústria nacional, e ela propõe que se reforce o Estado central, através de uma transferência de competências em detrimento das coletividades locais, com uma diminuição das dotações do Estado.

"O Estado é uma máquina para manter a dominação de uma classe sobre outra" "Sobre o Estado", Lênin, 1919). Esse Estado deve estar ao serviço do capitalismo e adotar suas normas; ele deve fazer "um esforço de organização e de eficiência... para modernizar e racionalizar o funcionamento dos serviços públicos comerciais". Trata-se então, de reforçar os órgãos repressivos do Estado, de tal modo que ele possa assegurar seu papel de proteção dos interesses capitalistas, com uma revalorização do orçamento da justiça (com a proibição para os juristas de se sindicalizar e de se comprometer politicamente), uma revalorização da polícia (com a organização de uma guarda nacional de 50 000 pessoas disponíveis imediatamente para reprimir as lutas sociais; um reforço dos efetivos da polícia de rua "dotados" do direito de matar - "legítima defesa"), revalorização do exército (sobretudo pela construção de um novo porta-aviões, o aumento do financiamento pelos antigos combatentes), a construção de novas vagas nas prisões, o aumento da responsabilidade penal para menores (associada à supressão de ajudas 
sociais, se elas existirem). A FN concebe assim o reforço do aparelho repressivo a serviço da pequena burguesia e do capital industrial nacional.

\section{Um programa destinado a enganar os trabalhadores, contra as organizações operárias e para uma associação capital- trabalho}

Enquanto que Jean-Marie Le Pen conservava um discurso mais abertamente pro-capitalista do que a tradição fascista que se dirige aos trabalhadores, Marine Le Pen, sem nada mudar, reinicia essa prática; Nicolas Sarkozy, o presidente da república anterior e o atual presidente François Hollande, não deixaram de perceber esse dado. O primeiro disse: "Marine Le Pen é de extrema-esquerda, seu programa econômico é o mesmo de Jean-Luc Mélenchon" (discurso de Sarkozy em Nancy, em 3 de novembro de 2014); e Fr. Hollande disse "A senhora Le Pen fala como em um panfleto do Partido comunista dos anos 70" (Canal+, 19 de abril de 2015). Ela própria cultiva a ambiguidade declarando que "a extrema-esquerda faz com frequência uma boa constatação, mas ela não vai ao final da lógica" (Journal du dimanche, 2 de novembro 2014).

Mesmo que a FN julgue que o "o custo do trabalho", isto é, o salário direto e diferido seja muito elevado, ela propõe certas medidas que "fingem" dirigir-se aos trabalhadores; entre elas o restabelecimento da indexação dos salários do sistema privado e ainda do mínimo para a velhice ( $3^{\mathrm{a}}$ idade), ambos sobre a inflação; assim como também o aumento do ponto de índice para os funcionários de categoria C. A FN propõe acabar com as políticas da austeridade que estão em curso dentro da zona do euro, acusando- as de afetar muito "as classes populares e médias, os aposentados, os funcionários, os PME/ $P M I$ ”. Ela propõe reduzir a 40 o número de anuidades de cotização necessárias para perceber aposentadorias com taxa plena, e de trazer de volta, progressivamente a idade de aposentadoria aos 60 anos. Ela propõe aumentar a base tributária aos ganhos do capital para financiar certas prestações de natureza social.

Ela, no entanto, não denuncia a "fraude fiscal" - da qual Jean-Marie Le Pen, aliás, acaba de ser culpado - (uns) ricos capitalistas não pagando nem querendo pagar os impostos, cuja soma total (dessa fraude) é estimada em mais de 80 bilhões de euros; trata-se, na realidade de reduzir o salário diferido dos trabalhadores, reforçando o controle dos desempregados, posto que a FN visa "o não respeito para um solicitador de emprego das obrigaçóes impostas pelo Pôle emploi seja verificado mais seriamente".

Assim, atacando os trabalhadores, a FN não acusa o capitalismo nem a classe capitalista, mas a zona do euro, e é por isso que ela propõe que a França "ponha seu veto aos inúteis e ruinosos planos de desencalhe dos países vitimas do euro" (programa). $\mathrm{Na}$ realidade, afirmando que "a empresa, o empresário e o assalariado estão no coração da vida econômica do país”, ela cria a ilusão de uma convergência de interesses e de uma aliança entre capital e trabalho. Tal posição leva em si várias consequências concretas. Trata-se, antes de mais nada, na tradição fascista, de substituir os sindicatos operários pelos sindicatos corporativistas: a FN preconiza uma "grande reforma de sindicatos, que suprime o monopólio de representatividade instituido depois da liberação ", modificada as "modalidades de eleiçôes dos representantes dos assalariados", de tal maneira que os sindicatos sejam "mais afeitos a entrar em lógicas de concertação construtivas e menos tentados a recorrer a uma relação de forças". Tal associação capital-trabalho passa pela atribuição aos assalariados de "uma parte de propriedade na empresa... permitindo 


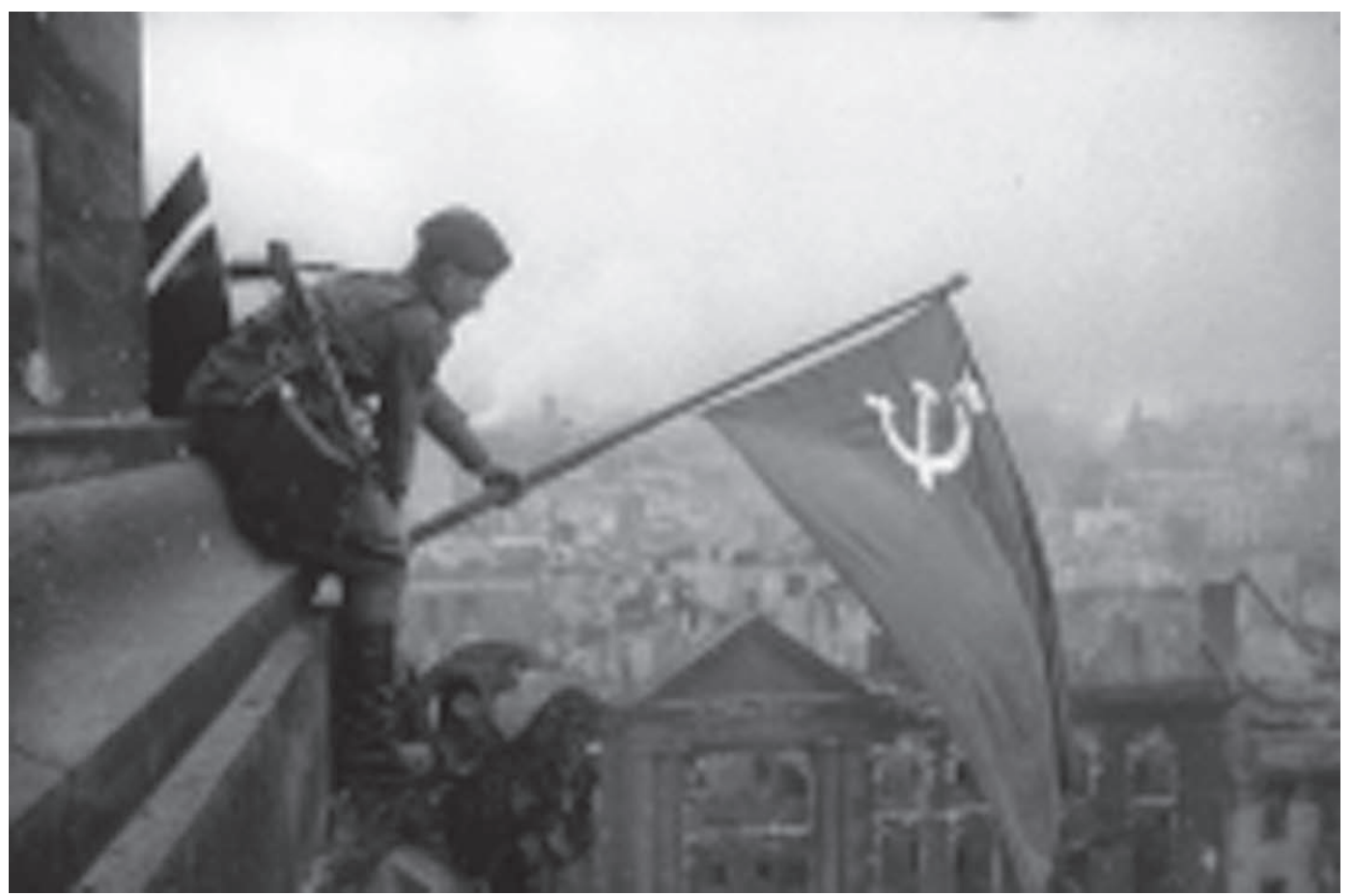

Bandeira vermelha no Reichstag, 1945.

o pago de dividendos", seguramente no lugar de uma parte do salário, tornando assim as percepções dos assalariados dependentes de sua exploração, "sem direito de voto", precisamente para evitar que os assalariados tenham qualquer coisa a dizer sobre o modo de funcionamento da empresa. A FN propõe igualmente a instauração, de modo completamente explícito, do trabalho gratuito, apelando para "o exército de voluntários benévolos, que não pedem nada, mas que estarão simplesmente desejosos e felizes em poder transmitir seus talentos às jovens gerações".

Os objetivos da FN podem resumir-se a: aumentar de maneira clara e direta a taxa de mais-valia para melhorar a taxa de lucro das empresas capitalistas nacionais.

\section{Uma preferência nacional, ao mesmo tempo contra os trabalhadores imigrados e contra a concorrência internacional}

A ofensiva da FN contra os trabalhadores passa por um discurso que tem como objetivo dividi-los. É por isso que esses ataques se concentram contra o estrangeiro, e em particular contra os trabalhadores estrangeiros. A FN propõe reduzir os direitos dos trabalhadores estrangeiros ao limitar o benefício das medidas sociais aos trabalhadores franceses, instaurando um prazo de carência, de um ano de residência contínua na França, e de cotização, para então ter o benefício da Previdência Social, suprimindo a ajuda médica do Estado reservada aos migrantes indocumentados; suprimindo o direito ao mínimo para a velhice ou a terceira idade, para os estrangeiros que trabalharam e cotizaram menos de dez anos na França; suprimindo o reagrupamento familiar - um dos três motivos que autorizam a imigração regular (junto ao motivo Professional e ao motivo estudos), - reduzindo assim, "drasticamente", o número daqueles que demandam asilo e que são autorizados a estar em território francês - limitando assim a livre circulação de pessoas com uma revisão dos acordos de Schengen -; reduzindo ainda a duração da cédula de estadia de 10 anos para três 
anos; enfraquecendo as associações de defesa dos imigrados (através de uma nova redução ou reescritura da convenção europeia dos direitos do homem); suprimindo o direito do solo; limitando as naturalizações; proibindo a dubla nacionalidade para as pessoas provenientes de países fora da União Europeia; suprimindo a possibilidade de regularização dos indocumentados. O objetivo é, então, o de dividir por vinte a imigração legal (de 200000 a 10000 entradas) em cinco anos.

A pequena burguesia tradicional encontra-se confrontada aos trabalhadores, mas também diante da concorrência estrangeira, e esta é a razão pela qual a FN preconiza a preferência nacional, notadamente com uma lei "compremos francês" (em outras palavras "só devemos consumir o que é francês"), fazendo de tal maneira que, a administração se abasteça em mercadorias nacionais; uma "incitação" para as empresas "priorizar no emprego... das pessoas que têm a nacionalidade francesa"; uma lei para forçar o Polo Emprego a propor... os empregos disponíveis aos franceses que demandam um emprego; ampliando "a lista de empregos... reservados às pessoas tendo a nacionalidade francesa"; uma modificação de imposto sobre as empresas para assim encorajar o reinvestimento prioritário dos benefícios na França; o estabelecimento de uma prioridade nacional para o acesso à moradia social. Contra a concorrência internacional, a FN recomenda direitos de alfândega e quotas de importação.

O adversário que o FN gosta mais de apontar é a União Europeia. É para ela questão de anulação da contribuição neta do Estado francês ao budget (orçamento) da União Europeia; de cessar com o uso do euro e voltar às moedas nacionais em direção a uma desvalorização competitiva. Seria questão, com um novo ministério das Soberanias, de renegociar os tratados da União Europeia para "restaurar a soberania nacional no conjunto dos campos onde ela desapareceu". A FN privilegia "uma associação livre de Estados europeus", ao "restabelecer a primazia do direito nacional sobre o direito europeu”, como se ele tivesse sido suprimido. Assim, longe de atacar o capital do qual ela é uma das organizações como partido, a FN defende o capitalismo francês contra os capitalismos de outros países.

\section{Conclusão}

Faz parte da tradição fascista o fato de que a FN se dirige em primeiro lugar à pequena burguesia fragilizada pela concorrência internacional, para defender na realidade o capital industrial nacional enfraquecido pelo progresso do capital financeiro, e com esse fim conseguir reforçar as funções repressivas do Estado. Considerando-se o anterior, este partido é um inimigo dos trabalhadores - ao procurar enganá-los propondo certas medidas, ele é favorável a um enfraquecimento dos sindicatos operários, favorecendo por sua vez os sindicatos corporativistas, no sentido de uma associação entre capital e trabalho. Finalmente, com uma política de preferência nacional, a FN procura dividir a classe operária, tomando por bodes expiatórios os trabalhadores estrangeiros, e enganando-os ao designar a União Europeia como culpada. A FN é, portanto, um partido burguês; o programa que ela defende está, sem ambiguidade, ao serviço da classe capitalista nacional; esse partido é, por essas razões, um inimigo dos trabalhadores.

\section{Bibliografia}


FRONT NATIONAL (2013), Notre projet. Programme politique du Front national, http://www.frontnationalcom/pdf/Programme.pdf.

LENIN, Vladimir (1976 [1919]), Euvres Tome 29 mars-août 1919, Éditions sociales.

« Manifesto dei Fasci italiani di combattimento », Il Popolo d'Italia, 6 Junho 1919. STEINERT, Marlis (1972 [1920]), L'Allemagne nationale-socialiste, 1933-1945, Richelieu.

TROTSKY, Léon (2015), Contre le fascisme 1922-1940, Syllepses. 